\title{
Psychosomatic Medicine: Emerging Trends and Perspectives
}

\author{
Giovanni A. Fava ${ }^{a}$ b Nicoletta Sonino ${ }^{c}$ \\ a Department of Psychiatry, State University of New York at Buffalo, N.Y., USA; bDepartment of Psychology, \\ University of Bologna, and 'Department of Medical and Surgical Sciences, University of Padova, Italy
}

\section{Key Words}

Psychosomatic medicine - Mind-body medicine •

Alternative medicine $\cdot$ Behavioral medicine $\cdot$ Health Psychology - Quality of life .

Psychoneuroendocrinology · Stress, psychological • Depressive disorder · Psychological well-being

\begin{abstract}
Developments have occurred in all aspects of psychosomatic medicine. Among factors affecting individual vulnerability to all types of disease, the following have been highlighted by recent research: recent and early life events, chronic stress and allostatic load, personality, psychological well-being, health attitudes and behavior. As to the interaction between psychological and biological factors in the course and outcome of disease, the presence of psychiatric (DSM-IV) as well as subclinical (Diagnostic Criteria for Psychosomatic Research) symptoms, illness behavior and the impact on quality of life all need to be assessed. The prevention, treatment and rehabilitation of physical illness include the consideration for psychosomatic prevention, the treatment of psychiatric morbidity and abnormal illness behavior and the use of psychotropic drugs in the medically ill. In the
\end{abstract}

\begin{tabular}{ll}
\hline KARGER & ( ) 2000 S. Karger AG, Basel \\
0033-3190/00/0694-0184\$17.50/0 \\
$\begin{array}{l}\text { Fax +4161306 12 34 } \\
\begin{array}{l}\text { E-Mail karger@karger.ch } \\
\text { www.karger.com }\end{array}\end{array}$ & $\begin{array}{l}\text { Accessible online at: } \\
\text { www.karger.com/journals/pps }\end{array}$
\end{tabular}

past 60 years, psychosomatic medicine has addressed some fundamental questions, contributing to the growth of other related disciplines, such as psychoneuroendocrinology, psychoimmunology, consultation-liaison psychiatry, behavioral medicine, health psychology and quality of life research. Psychosomatic medicine may also provide a comprehensive frame of reference for several current issues of clinical medicine (the phenomenon of somatization, the increasing occurrence of mysterious symptoms, the demand for well-being and quality of life), including its new dialogue with mind-body and alternative medicine.

Copyright $@ 2000$ S. Karger AG, Basel

The term 'psychosomatic' was introduced by Heinroth in 1818 , but it is not until the 1930s that modern psychosomatic medicine was founded [1]. It resulted from the confluence of two concepts having an ancient tradition in Western thought and medicine: those of psychogenesis of disease and of holism [1]. The idea of psychogenesis characterized the first phase of the development of psychosomatic medicine (1930-1960) and resulted in the concept of psychosomatic disease (a physical illness believed to be caused by psychological factors, such as peptic ulcer).

\footnotetext{
G.A. Fava, MD

Dipartimento di Psicologia, Università degli Studi di Bologna

Viale Berti Pichat 5

I-40127 Bologna (Italy)

Fax +39051243086
} 
Despite early criticism [2], the psychogenic postulate indeed exerted a considerable seduction in view of its explanatory power, particularly in a field then dominated by psychoanalytic investigators. Wittkower [3] remembered the fifties as characterized by a "tremendous excitement which pervaded the annual conventions of the American Psychosomatic Society; the meetings were crowded, the papers were enthusiastically received and representatives of several leading foundations were present. One had the impression that a breakthrough in medicine had occurred. Diseases regarded previously as obscure of origin, we believed, had found an explanation and the prospects of treating them by psychotherapy appeared bright' [3, p. 312]. However, these great expectations did not survive the test of scientific evidence. Progressively internists left the field [3], and a profound crisis seemed to pervade psychosomatic medicine. Engel, Lipowski and Kissen deserve credit for setting, in the sixties, the ground for its renaissance under more appropriate guidelines.

Engel [4] developed a multifactorial model of illness, later subsumed under the rubric of 'biopsychosocial' [5]. It allows illness to be viewed as a result of interacting systems at the cellular, tissue, organismic, interpersonal and environmental levels. As a result, the study of every disease must include the individual, his body and his surrounding environment as essential components of the total system [5]. The various social factors involved may range from the socioeconomic status (e.g. poverty, nutritional deprivation, loss of social support) to toxic environmental exposure [6,7], in what constitutes a truly ecological viewpoint. In this setting, psychosocial factors may operate to facilitate, sustain or modify the course of disease, even though their relative weight may vary from illness to illness, from one individual to another and even between two different episodes of the same illness in the same individual. These components may influence susceptibility to disease by activating a variety of CNS pathways [8]. Disciplines such as psychoneuroendocrinology and psychoimmunology, which originally stemmed from psychosomatic research, aim at unraveling the complex balance between emotions and disease [9-11].

Lipowski gave an invaluable contribution in setting the scope, mission and methods of psychosomatic medicine [12]. He identified three interrelated facets: (1) it is a scientific discipline concerned with the study of the relationships of biological, psychological and social determinants of health and disease; (2) it embodies a holistic approach to the practice of medicine, and (3) it encom- passes consultation-liaison psychiatry [13]. Both Engel and Lipowski $[1,4]$ criticized the obsolete notion of psychogenesis, since it was incompatible with the doctrine of multicausality, which constitutes a core postulate of current psychosomatic medicine.

Kissen provided a better specification of the term psychosomatic. 'It would appear possible for an illness generally thought of as being 'psychosomatic' to be 'non-psychosomatic' in certain individuals. Likewise an illness not generally thought as 'psychosomatic' may be psychosomatic in some individuals' [14, p. 40]. He thus clarified that the relative weight of psychosocial factors may vary considerably from one individual to another within the same illness and underscored the basic conceptual flaw of considering diseases as homogeneous entities. Instead of asking: 'Which psychological factors give rise to which illnesses?', Kissen suggested to ask: 'Who are the patients within a given illness population for whom psychosocial variables are of primary significance?'.

The growth and development of consultation-liaison psychiatry throughout the world [15] provided a strong clinical impetus to psychosomatic research and practice. At the same time, however, it increased the psychiatric connotation of the field. Up to the seventies, psychosomatic medicine was the only site for research at the interface between medicine and behavioral sciences. In those years, however, behavioral medicine developed [16] as an interdisciplinary field that integrates behavioral and biomedical knowledge relevant to health and disease. It provided a room for the increasing number of psychologists dealing with basic laboratory research on the neural and humoral systems controlled by the brain, on visceral learning and on other aspects of behavior which lead to practical applications of medical significance [17]. Its main focus is on unhealthful behavior and risk factors (such as smoking and alcohol abuse), laboratory proof of effects of stress, visceral learning and behavior therapy in medical settings [17].

The last decade has witnessed an upsurge of interest in another related discipline, subsumed under the rubric of mind-body medicine, sharing the same holistic, biopsychosocial connotation with psychosomatic medicine [18]. However, the concept of mind-body medicine is inextricably linked to that of alternative therapy [19]. Unlike psychosomatic medicine, which has always been marginal to the lay public, mind-body medicine has been extremely successful in making key psychosomatic concepts such as the eclipse of the patient [20], the healing partnership [21] and self-care as primary care [22] popular. About one third of the American people use alternative medical ther- 
Table 1. Medical disorders that have been associated with stressful life events in controlled studies

Asthma

Diabetes

Graves' disease

Cushing's disease

Hypothalamic amenorrhea

Peptic ulcer

Inflammatory bowel disease

Functional gastrointestinal disorders

Myocardial infarction

Functional cardiovascular disorders

Autoimmune disease

Cancer

Infectious disease

Psoriasis, alopecia areata and urticaria

Headache

Cerebrovascular disease

Sudden death

apies (defined as interventions neither taught widely in medical schools nor generally available in hospital), and these percentages are on the rise (from $33.8 \%$ in 1990 to $42.1 \%$ in 1997) [23]. In addition, a large number of physicians are either referring to or practicing some of the bestknown forms of alternative medicine, such as acupuncture and herbal medicine [24].

\section{What Is Psychosomatic Medicine?}

Psychosomatic medicine provides a comprehensive framework for a holistic (biopsychosocial) consideration of patient care encompassing:

(1) the role of psychosocial factors in affecting individual vulnerability to all types of diseases;

(2) the interaction between psychosocial and biological factors in the course and outcome of disease;

(3) the application of psychological therapies to the prevention, treatment and rehabilitation of physical illness.

This framework, modified from the one originally proposed by Lipowski [1], will serve to highlight the areas where a psychosomatic integration may have important clinical and research implications. The emergence of mind-body medicine and its complex relationships with psychosomatic medicine and behavioral medicine make necessary to redefine the aims and methods of psychosomatic medicine, after Lipowski's reviews in 1977 [13] and 1986 [1].

\section{Psychosocial Factors Affecting Individual Vulnerability}

A number of factors have been implied to modulate individual vulnerability to disease.

\section{Recent Life Events}

The notion that events and situations in a person's life which are meaningful to him or her may be followed by ill health has been a common clinical observation. For instance, Bram [25] in 1927 reviewed 3,343 cases of exophthalmic goiter. In $85 \%$ of cases he detected 'a clear history of psychic trauma as the exciting cause of the disease'. These clinical observations, however, had considerable shortcomings: events may be the consequence rather than a cause of illness (due to its insidious development) and patients may not actually experience more events prior to illness, but simply recall more of them, in an 'effort after meaning'. The introduction of structured methods of data collection (and particularly semi-structured research interviews with high inter-rater reliability) and control groups has been a turning point in the research in the area [26]. Use of these methods, for instance, has allowed to substantiate the link between life events (discrete changes in the subject's social or personal environment, that should be external and verifiable rather than internal or psychological), and endocrine conditions [2731]. In Graves' disease, the evidence that ensues is pretty solid, since it is based on independent studies which obtained comparable results by using similar and reliable methods in different countries. Stressful life events may affect the regulatory mechanisms of neuroendocrine-immune functions in a number of ways [32-34]. Within a multifactorial frame of reference, stressful life events have been consistently associated with several medical disorders. Table 1 outlines the medical disorders for which controlled studies have pointed to a relationship [11, 2640].

\section{Chronic Stress and Allostatic Load}

Life changes are not the only source of psychological stress. Subtle and long-standing life situations should not too readily be dismissed as minor and negligible [41] since chronic, daily-life stresses may be appraised by the individual as taxing or exceeding his or her coping skills. Fur- 
ther, a number of factors may modulate the psychological response to stress [42], such as social support [43] and personality [44] and act by increasing the impact of stressful circumstances or by offering protection against their adverse effects [45].

McEwen and Stellar [36] proposed a formulation of the relationship between stress and the processes leading to disease, based on the concept of allostatic load: the cost of chronic exposure to fluctuating or heightened neural or neuroendocrine response resulting from repeated or chronic environmental challenge that an individual reacts to as being particularly stressful. It emphasizes the hidden cost of chronic stress to the body over long time periods, which acts as a predisposing factor for the effects of life changes [36]. Four situations are associated with allostatic load: frequent stress, failure to adapt to repeated stressors of the same type, inability to shut off allostatic responses after a stress is terminated and inadequate responses which trigger compensatory increases in other allostatic systems [46]. An important new line of research involves the use of concomitant biological measures of allostatic load, such as glycosylated proteins, coagulation/fibrinolysis markers and immune markers [47]. Johnston-Brooks et al. [48], for instance, associated household density as a chronic environmental stressor with cardiovascular reactivity as a marker of allostatic load and found a relationship with medical illness in children. The need of combining psychometric and biological measures in laboratory research involved with psychoneuroendocrinology of human disease has therefore emerged $[49,50]$.

\section{Early Life Events}

The role of early developmental factors in susceptibility to disease has been a frequent object of psychosomatic investigation [51]. Due to the difficulties in gathering retrospective information, considerable value has been achieved by psychosomatic studies concerned with animal models [52, 53]. Events such as premature separation from the mother have consistently resulted in development of physiological vulnerability [52]. This may reflect increased hypothalamic-pituitary-adrenal axis (HPA) activation: in fact, deprivation of the infant animal from maternal cure for prolonged periods of time results in increased concentration of immunoreactive $\mathrm{CRH}$ in the median eminence and of CRH mRNA expression in the paraventricular nucleus [54]. This has led to the hypothesis that early adverse life events (e.g. separation) or traumatic events in childhood (e.g. sexual abuse) may render the human individual more vulnerable to the effects of stress later in life, by long-lived alteration in CRH-con-
Table 2. Characteristic features of Type-A behavior

Excessive degree of involvement in work and other activities subject to deadlines

Sense of time urgency

Display of motor-expressive features indicating sense of being under the pressure of time

Hostility and cynicism

Irritable mood

Tendency to speed up physical activities

Tendency to speed up mental activities

High intensity of desire for achievement and recognition

High competitiveness

taining neural circuits [55]. This may have important implications for HPA-driven disorders such as depression [55] and Cushing's disease [56]. A similar hypothesis has been suggested as to prolactin secretion [57]. The past decade has witnessed an upsurge of interest in the association of childhood physical and sexual abuse with medical disorders [58], pioneered by Engel [59] in the fifties as to chronic pain. Whether sexual abuse results, through neuroendocrine mechanisms, in the development of physiological vulnerability or affects illness behavior [60], or both, is a research question that can only be addressed by proper psychosomatic integration.

\section{Personality}

The notion that personality variables can affect vulnerability to specific diseases was prevalent in the first phase of the development of psychosomatic medicine (19301960), and was particularly influenced by psychoanalytic investigators, who believed that specific personality profiles underlay specific 'psychosomatic diseases'. This hypothesis was not supported by subsequent research [1]. Two personality constructs that can potentially affect general vulnerability to disease, however, have attracted considerable attention. One is concerned with the relationship between coronary heart disease and the so-called Type-A behavior pattern. People manifesting this pattern display some or all the characteristics listed in table 2 [61]. A large number of studies have been conducted in the past three decades on the pathogenetic role of Type-A behavior in coronary heart disease [39, 62-64]. Various methods of assessment have been used, and the results have been rather controversial; hostility and time urgency appeared to be two key components [62,63]. A substantial problem lies in the fact that the definition of Type-A 
Table 3. Characteristic features of alexithymia

Inability to use appropriate words to describe emotions

Tendency to describe details instead of feelings

Lack of a rich fantasy life

Thought content associated more with external events rather than fantasy or emotions

Unawareness of the common somatic reactions that accompany the experience of a variety of feelings

Occasional but violent and often inappropriate outbursts of affective behavior

Table 4. Dimensions of psychological well-being

Self-acceptance (a positive attitude toward self)

Positive relations with others (warm, satisfying, trusting relationships)

Autonomy (self-determination and independence)

Environmental mastery (sense of mastery and competence in managing the environment)

Purpose in life (goals and a sense of directedness)

Personal growth (feeling of continued development)

behavior consists of a mixture of state and trait features, which cannot be ascribed to stable personality aspects [61]. However, the bulk of the literature seems to indicate that there is a pattern of behavior that is associated with coronary heart disease, even though this does not apply to every case and it cannot be readily identified [62, 65].

The other psychological construct is alexithymia. This concept was introduced by Sifneos [66] to describe an impoverished fantasy life with a resulting utilitarian way of thinking and a characteristic inability to use appropriate words to describe emotions. The characteristic features of alexithymia are outlined in table 3 [61]. The inhibition of emotional expression and particularly a life-long tendency to suppress anger have been found to involve an increased risk for a variety of health problems, both using the alexithymia [66] or similar $[67,68]$ psychological constructs. The findings concerned with cancer stemmed from a study finding that women aged under 50 who were subsequently diagnosed as having breast cancer showed significantly higher levels of suppressed anger than those who turned out to have benign tumors [69]. However, despite advances in our understanding of the relationship between the brain and the immune system $[9,10]$, it is premature to conclude that a relationship between suppressed emotion and cancer does exist. Personality traits may be related to the course of cancer, since the cellular mechanisms involved in the progression and metastasis of tumors differ from those that initiate the transformation of cells [70]. In a study [71], it was found that recurrence of breast cancer was significantly less common in women reacting to the disease with denial or a fighting attitude than among those displaying stoic acceptance or feelings of helplessness or hopelessness. Despite more than two decades of research, alexithymia is still a controversial concept, particularly in its assessment [72], psychophysiological correlates [73] and relationships with other affective components [74-78].

\section{Psychological Well-Being}

Positive health is often regarded as the absence of illness, despite the fact that, half a century ago, the World Health Organization defined health as a 'state of complete physical, mental and social well-being and not merely the absence of disease or infirmity' [79]. Ryff and Singer [80] remark that, historically, mental research is dramatically weighted on the side of psychological dysfunction, and that health is equated with the absence of illness rather than the presence of wellness. Research on psychological well-being has indicated that it derives from the interaction of several intercorrelated dimensions [80], as described in table 4. There is substantial evidence [81-83] that psychological well-being plays a buffering role in coping with stress, has a favorable impact on disease course, and has important immunological and endocrine connotations. For instance, maintenance of psychological wellbeing following the onset of breast cancer implies longer survival time [84], whereas impaired well-being tends to shorten survival time [85]. Other examples may be concerned with the role of optimism and coping style in transplantation outcome [86], anxiety and hope in the course of medical disorders [87], and the relationship between life satisfaction and cardiological variables [88, 89].

\section{Health Attitudes and Behavior}

There is growing awareness that certain personality habits, such as smoking cigarettes, drinking alcohol and eating a diet rich in cholesterol and saturated fats, may have a considerable impact on health. Beliefs about risks associated with certain health-damaging behaviors are not necessarily associated with the absence of those health risk behaviors. In a survey of health behaviors in young adults in 8 countries throughout Europe [90], those who engaged more in drinking and smoking were just as much 
aware of the negative consequences of these health-damaging behaviors as people who did not engage in them. On the other hand, beliefs about the positive effects of healthprotective behaviors, such as eating a low-fat diet, exercise, safety practices and participating in health screening exams (e.g. testing for breast or prostate cancer) were strongly associated with their practice [90]. This exemplifies the psychosomatic complexity of both health-damaging and health-promoting behaviors [91].

\section{Psychosocial Correlates of Medical Disease}

Psychosocial and biological factors interact in a number of ways in the course of medical disease. Their varying influence determines the unique quality of the experience and attitude of every patient in any given episode of illness [92].

\section{Psychiatric Disturbances}

The potential relationship between medical disorders and psychiatric symptoms ranges from a purely coincidental occurrence to a direct causal role of organic factors - whether medical illness or drug treatment - in the development of psychiatric disturbance. The latter is often subsumed under the rubric of organic mental disorders whose key feature is the resolution of psychiatric disturbances upon specific treatment of the organic condition [93]. Psychosomatic medicine has pioneered the study of this clinical area (including delirium and dementia), that - up to the eighties - was largely neglected in psychiatry [94]. Major depression has emerged as an extremely important source of comorbidity in medical disorders $[95,96]$. A depressed mood may in fact influence how a person experiences the pathological process and his or her interaction with others, including medical staff. In particular:

(1) The presence of depressive symptoms in association with chronic medical illness was found to affect quality of life and social functioning and lead to increased healthcare utilization $[95,96]$.

(2) Depression was found to have an impact on compliance. Many cases of 'suicide by default' in the medical population (i.e. the deliberate omission of therapeutic, dietary and other measures necessary to sustain life or prevent the progress of pathology) may mask a major depressive disorder [97]. Examples include diabetic patients who stop taking insulin, those who resume strenuous work after myocardial infarction and those who withdraw from chronic hemodialysis [97].
(3) Research has suggested that depression may increase susceptibility to medical disease $[95,96]$. The evidence is particularly impressive in cardiovascular disease [98]. Clinical depression appears to be an independent risk factor for coronary heart disease [99] and to affect mortality rate after myocardial infarction [100]. Depression has been suggested to be also a marker of disease severity, i.e. in pituitary-dependent Cushing's disease, the presence of depression was associated with severity of clinical presentation [101] as well as entailed prognostic value (patients were more likely to relapse after a successful pituitary microadenomectomy if they presented with depression at the time of surgery) [102].

(4) Functional medical symptoms are extremely common in medical practice. Their association with depression has been consistent, regardless of the design of the study [103]. Depressed patients tend to have more somatic symptoms than nondepressed individuals, and somatizers tend to be more depressed than patients with physical disease [103]. The case of depression exemplifies the importance of detecting and treating psychiatric comorbidity in the setting of medical disease.

\section{Psychological Correlates}

Current emphasis in psychiatry is on assessment of symptoms resulting in syndromes identified by diagnostic criteria (DSM) [104]. However, there is emerging awareness that subclinical psychiatric symptoms may have a considerable impact on quality of life and entail pathophysiological and therapeutic implications [105-108]. This particularly applies to the setting of medical disease, where most psychological symptoms cannot be assigned a suitable rubric according to psychiatric diagnostic criteria [82]. The case of hostility is particularly indicative. A considerable body of evidence has suggested a pathogenetic role for anger, hostility and irritable mood in physical illness [44, 107]. Most of this evidence stemmed from hostility as a risk factor in cardiovascular medicine [109]. For instance, in a prospective study of the progression of carotid atherosclerosis, cynical distrust and anger, in addition to previously established risk factors (i.e. serum low-density lipoprotein cholesterol concentration, smoking) predicted outcome [110]. The association between low serotonin function and hostility and anger [111] may provide a neurobiological framework for these unfavorable effects. Serotonin may in fact affect factors such as macrophage activation, plasminogen activation inhibitor, platelet activation, cytokines and natural killer cell activity [112]. Similar considerations can be made as to a psychological state characterized by the giving-up 
complex, helplessness and hopelessness, demoralization [113], which has been found to facilitate the onset of disease to which the individual was predisposed. Such a subsyndromal state cannot be identified with psychiatric categories [114]. Both demoralization and irritability may be part, in association with fatigue, of another psychological state, labeled as vital exhaustion, which was found to be an independent risk factor for myocardial infarction [115]. Unfortunately, several psychosomatic constructs, related to psychological characteristics such as irritability and demoralization, have not resulted in operational tools whereby psychosocial aspects of medical diseases can be differentiated. This has led to the development of a set of Diagnostic Criteria for Psychosomatic Research (DCPR) by an international group of investigators [61]. These criteria aim to identify alexithymia, Type-A behavior, disease phobia, thanatophobia, health anxiety, illness denial, functional somatic symptoms secondary to a psychiatric disorder, persistent somatization, conversion, anniversary reaction, irritable mood and demoralization. In this issue [116], these criteria were found to be more suitable than DSM-IV criteria in identifying psychological distress in a medical population. The conceptual model that underlies the DCPR is devoid of pathogenetic implications (unlike several other psychosomatic constructs) and emphasizes the varieties of associated somatic and mental responses that individuals offer to life situations (psychosomatic syndromes). Psychosomatic investigators have generally attempted to demonstrate that a certain psychological characteristic ' $\mathrm{x}$ ' is more prevalent in the condition ' $a$ ' compared to the condition ' $b$ '. Even when they do find a significant difference by reliable statistical and psychometric methods, this does not mean that every patient with ' $a$ ' also presents with ' $x$ ' and that a patient with ' $b$ ' may not present with ' $x$ ' features. It is their association, not their specificity, which may matter. Bjorntorp [117], for instance, has suggested that an excessive androgen production in women, as occurs in polycystic ovary syndrome, may be associated with physiological and psychological characteristics which are typically found in men. Such psychosomatic combination (the android woman) may pave the way for an increased risk of developing hypertension, non-insulin-dependent diabetes mellitus and cardiovascular disease, as was found also in epidemiological studies in the general population [117]. Each component of this psychosomatic combination, taken by itself, would not necessarily lead to the same risky condition. The DCPR are thus aimed at translating psychosocial characteristics observed in various medical diseases in diagnostic criteria, which may entail clinical (prognos- tic and therapeutic) value, and be studied across disorders.

\section{Illness Behavior}

Lipowski remarks that once the symptoms of a somatic disease are perceived by a person, 'or he has been told by a doctor that he is ill even if symptoms are absent, then this disease related information gives rise to psychological responses which influence the patient's experience and behavior as well as the course, therapeutic response and outcome of a given illness episode' [97]. The study of illness behavior, defined as the ways in which individuals experience, perceive, evaluate and respond to their own health status [118], has yielded important information in medical patients [119]. It was translated clinically by Pilowsky's concept of abnormal illness behavior, defined as the persistence of a maladaptive mode of perceiving, experiencing, evaluating and responding to one's health status, despite the fact that a doctor has provided a lucid and accurate appraisal of the situation and management to be followed if any, with opportunities for discussion, negotiation and clarification, based on adequate assessment of all relevant biological, psychological, social and cultural factors [120]. The two main forms of abnormal illness behavior (illness affirming and illness denying) have several common clinical expressions in clinical practice. They range from hypochondriasis and disease phobia [119] to illness denial $[121,122]$ and lack of compliance $[123,124]$. In recent years, there has been increasing interest in assessing patients' perceptions of the impact of illness $[125,126]$. The integration of measurements of psychopathology of illness behavior, such as those provided by Kellner's Illness Attitudes Scales [119] and Pilowsky's Illness Behavior Questionnaire [120], with those concerned with patients' perceptions appears to be an important task of current psychosomatic research.

\section{Quality of Life}

Quality of life, particularly in chronic diseases, has became the focus of an increasing number of publications. While there is neither a precise nor agreed definition of quality of life, research in this area seeks essentially two kinds of information, the functional status of the individual and the patient's appraisal of health [127]. The concept stems from the fact that the measures of disease status alone are insufficient to describe the burden of illness and that the subjective health status (e.g. well-being, demoralization, difficulties fulfilling personal and family responsibilities) is as valid as that of the clinician when it comes to evaluating outcomes [127-130]. The concept of 
quality of life is substantially based on the classic psychosomatic concept of disease: 'How a person experiences the pathological process, what it means to him, and how this meaning influences his behavior and his interaction with others are all integral components of disease viewed as a total human response' [131]. Unfortunately, investigators dealing with quality of life seem to discard psychosomatic research failing to incorporate the methodological insights acquired by this discipline in the past decades [132]. Not surprisingly, the quality of quality of life measurements is often rather poor [133].

\section{Application of Psychological Therapies to Medical Diseases}

Psychological interventions in the medically ill encompass the use of psychotherapeutic strategies, psychopharmacological interventions and preventive strategies. They may be performed by a variety of health professionals (psychiatrists, psychologists, nurses, primary care physicians). In the seventies and eighties, the role of consultation-liaison psychiatry has been particularly emphasized [134]. Its role in providing psychiatric care in the general hospital, in education and in research is still considerable [135], yet its potential has probably been overestimated. In the meanwhile, the importance of the interaction of psychiatric, psychosomatic or behavioral medicine services with primary care has progressively increased [136]. Another valuable source of collaboration has been identified in medical-psychiatric units for the treatment of patients who require acute hospital care and cannot be managed adequately either in a standard psychiatric ward or in medical-surgical wards of the general hospital [137].

\section{Psychosomatic Prevention}

In a multifactorial frame of reference, consideration of the role of stressful life events, allostatic load and healthdamaging behavior, lends itself to important preventive efforts. Two important causes of allostatic load appear to be isolation and lack of control in the work environment [46]. Theorell [138] has illustrated the effectiveness of programs for improving the ability to cope with difficult life situations, particularly involving the work environment, and to counteracting loneliness among pensioners. A number of psychological treatments have been shown to be effective in health-damaging behaviors, such as smoking [139].
Table 5. Medical conditions in which shortterm psychotherapies have been found to be effective in randomized controlled trials

Chronic pain

Chronic fatigue syndrome

Coronary heart disease

Hypertension

Tension headaches

Diabetes

Cancer

Asthma

Epilepsy

Obesity

Peptic ulcer

Irritable bowel syndrome

Inflammatory bowel disease

HIV infection and AIDS

Arthritis

Preparation to medical procedures

\section{Treatment of Psychiatric Morbidity}

There is evidence $[95,96,140,141]$ that psychiatric disorders and particularly major depression are frequently unrecognized and untreated in medical settings, with widespread harmful consequences for the individual and the society. Treatment of psychiatric comorbidity such as depression, whether pharmacological or psychotherapeutic, was found to favorably affect outcome and compliance $[95,96]$. Psychiatric disorders in the medically ill may, however, require treatment strategies that are different from those endorsed in clinical psychiatry. Use of psychotherapeutic strategies (cognitive-behavioral therapy, stress management procedures, brief dynamic therapy) in controlled investigations has yielded a substantial improvement either in quality of life and/or in coping and/or in the course of disease in a number of medical disorders, as listed in table 5 [139, 142-145]. Examples of these strategies are concerned with interventions that increase social support and enhance coping in patients with breast cancer [84], lymphomas [146] and malignant melanoma [147]; treatment of depression by cognitive behavioral therapy in type 2 diabetes mellitus [148], and cognitive behavioral management for noncardiac chest pain [149]. At times, the interventions were as simple as writing about stressful experiences, as in asthma and rheumatoid arthritis [150].

Research on psychotherapy has disclosed some common therapeutic ingredients that most of the psychothera-

Psychother Psychosom 2000;69:184-197 
Table 6. Nonspecific therapeutic ingredients that are shared by most forms of psychotherapy

\begin{tabular}{lll}
\hline Ingredients & Characteristics \\
\hline 1 & Attention & $\begin{array}{l}\text { the therapist's full availability for specific times } \\
\text { the patient's opportunity to ventilate thoughts } \\
\text { and feelings } \\
\text { an emotionally charged, confiding relationship } \\
\text { with a helping person }\end{array}$ \\
3 & High arousal & $\begin{array}{l}\text { a plausible explanation of the symptoms } \\
\text { a ritual or procedure that requires the active } \\
\text { participation of both patient and therapist and } \\
\text { that is believed by both to be the means of } \\
\text { restoring the patient's health }\end{array}$ \\
& Interpretation
\end{tabular}

peutic techniques share, and that are outlined in table 6 $[151,152]$. These ingredients may also apply to routine medical practice. In a pioneer study [153], a small amount of individual attention and education (what to expect during the postsurgical period) by the anesthetist resulted in a significantly lower requirement of postsurgery analgesia and in a shorter hospital stay compared to a control group submitted to routine postsurgical care as usual. The nonspecific therapeutic ingredients of table 6 can thus be used with specific effects and do not require highly specialized training.

Awareness of nonspecific ingredients should not lead, however, to the conclusion that all psychotherapeutic interventions yield similar results in the medically ill. For instance, the effects of relaxation were found to be superior to attention and education in preparation for surgery [154]. Marks [155] has outlined how specific cognitive behavioral strategies may yield, by different methods, a common therapeutic change (increase in sense of control) that is of paramount importance in mood and anxiety disorders. Astin et al. [156] reviewed the implications of the construct of control for health care. Since illness frequently results in feelings of loss of control, gaining a sense of mastery can help patients to cope with illness. Several studies, however, suggest that it is important to match control strategies to patient styles and preferences [156]. As a result, different psychotherapeutic techniques, which are aimed at enhancing control, should be available in the setting of medical disease.

Improvement of psychological well-being by means of a specific psychotherapeutic strategy defined as wellbeing therapy $[157,158]$ is another area of interest, in view of the protective effects of well-being as to life adversities [85]. It is conceivable, even though yet to be tested, that well-being therapy may be particularly valuable in patients whose disease has determined a loss. In this context, loss refers not just to body parts and functions actually lost, but also to deprivations of personally significant needs and values, such as self-esteem, security and satisfaction [131].

Lipowski [92] outlined six stages of illness: symptom perception, decision making, medical contact, acute illness, convalescence and rehabilitation, and chronic illness or disability. It is conceivable that application of psychotherapeutic techniques may follow these stages and be specifically geared for them [159].

\section{Treatment of Abnormal Illness Behavior}

For many years, abnormal illness behavior has been viewed mainly as an expression of personality predispositions and considered to be refractory to treatment by psychotherapeutic methods. There is now evidence, both of psychotherapeutic and pharmacotherapeutic nature, to challenge such pessimistic stance [103, 160, 161]. For instance, several controlled studies on psychotherapy [162-166] indicate that hypochondriasis is a treatable condition. Providing accurate information and the use of simple cognitive strategies, such as clarification of both previous faulty communications with physicians and common psychophysiological reactions (patients may in fact be unable to attribute somatic symptoms to anxiety) underlie treatment of hypochondriacal patients [103]. The application of these simple suggestions has yielded significant improvements in controlled studies concerned with functional medical disorders [103]. The correlation between abnormal illness behavior and health habits may have implications in preventive efforts. Indeed, individuals with hypochondriacal fears and beliefs were found to take worse care of their health than control subjects in several studies [167]. They may be so distressed by their belief of having an undiagnosed or neglected disease that behaviors that may yield benefits in the distant future appear to be irrelevant to them.

\section{The Use of Psychotropic Drugs in the Medically Ill}

Aside from the use of psychotropic drugs for treating psychiatric comorbidity in medical disease (e.g. the use of antidepressant drugs in patients with major depression), there is evidence from a number of double-blind placebocontrolled studies that psychotropic drugs may favorably affect the course and outcome of several medical conditions [168-170], such as peptic ulcer and chronic pain. 
Psychosomatic studies such as the ones concerned with the relationship between neurotransmitters and functional medical disorders [171] may shed some light on the underlying mechanisms. In view of the increasing awareness of the pathogenetic role of stressful life situations (resulting in disregulation of the HPA axis), a novel pharmacological strategy could be offered by the recent availability of CRH receptor antagonists [172]. Whether these agents may provide a decrease in psychophysiological activation that is superior to that entailed by benzodiazepines in functional medical disorders [168] is certainly an issue worthy of investigation.

\section{Conclusions}

In the past 60 years, psychosomatic medicine has addressed some fundamental questions about health and disease. Many of these questions were addressed well ahead of the current prevailing medical orientation. Disciplines such as psychoneuroendocrinology, psychoimmunology, consultation-liaison psychiatry, behavioral medicine, health psychology, as well as quality of life research, stemmed from the psychosomatic field. Even though they may now claim full autonomy, their psychosomatic linkages are crucial for their balanced developments. For instance, modification of health-damaging behavior in the name of public health, without a psychosomatic frame of reference, can make health psychology and behavioral medicine amenable to the risk of 'coercive healthism', which involves uninvited intrusions and zealous advocacy unlikely to entail a significant impact [173].

Nowadays, the concept of translational research (a sustained dialogue between clinicians and basic scientists) has achieved wide currency. Psychosomatic medicine as a field of inquiry has pioneered translational research. The research strategies that investigators brought to bear on psychosomatic questions (i.e. which life situations are more likely to increase the risk of becoming ill? What are the mediating psychological pathways and mechanisms whereby psychosocial factors may affect the organism? What are the effects of a specific illness on the person's psychological functions?) were strongly influenced by the prevailing climate of interest and success in the behavioral sciences. On the other hand, the flourishing of research in neuroscience offers unprecedented opportunities to psychosomatic medicine to update its scientific background [112].
Critical appraisal of current developments in clinical medicine is likely to underscore several areas which can potentially benefit from a psychosomatic approach. They include:

(1) Somatization. The tendency to experience and communicate psychological distress in the form of physical symptoms and to seek medical help for them [1] is a widespread clinical phenomenon that may involve up to $30-40 \%$ of medical patients. It may well be the most costly comorbidity [174]. Fourteen common physical symptoms are responsible for almost half of all primary care visits [175], but only $10-15 \%$ are found to be caused by an organic illness over a 1-year period.

(2) Mysterious symptoms. A significant proportion of problems presenting to a primary care physician cannot be assigned a suitable diagnostic rubric [176]. And when this latter takes the form of a functional medical disorder, it does not seem to prevent excess health care use and therapeutic frustration [103]. The need of new approaches to ambulatory care, encompassing the biological, psychological and social aspects of human disease, has emerged [177]. Not surprisingly, the past decade has witnessed an upsurge of use of alternative medicine and its underlying models [18-24].

(3) Quality of life. The need to include consideration of function in daily life, productivity, performance of social roles, intellectual capacity, emotional stability and wellbeing, has emerged as a crucial part of clinical investigation and patient care [127-133]. This has become particularly important in chronic diseases where cure cannot take place and also extends to family caregivers of chronically ill patients, whose emotional burden has become more and more manifest $[178,179]$, and health providers [180, 181]. Patients have become more and more aware of these issues. Their difficulties in coping with medical illness and its psychological consequences have indeed led to the development of several patients' associations.

There is also increasing emphasis on health promotion rather than simple disease prevention [182]. Commercial success of books on alternative medicine and positive practices speaks to the receptivity of the general public to these messages of health prevention and alternative medical models [83]. Two decades ago, Reiser [183] anticipated the success of oriental medical theory and practice in the Western world and identified psychosomatic medicine as the most suitable meeting ground for the two medical models. Indeed, the psychosomatic research background that has consolidated over the past decades in dealing with complex biopsychosocial phenomena [184, $185]$ is the ideal setting for testing the highly heteroge-

Psychother Psychosom 2000;69:184-197 193 
neous mixture of therapeutic practices that is part of alternative medicine.

As Wittkower [3] suggested, to accomplish its goals, psychosomatic medicine should be fully incorporated in the practice of medicine, and therefore be dedicated to its own 'dissolution'. We are still very far from accomplishing this [186].

\section{Acknowledgment}

This paper was supported in part by grants from Ministero dell'Università e della Ricerca Scientifica e Tecnologica (Roma, Italy) to G.A.F. and N.S.

\section{References}

1 Lipowski ZJ: Psychosomatic medicine: Past and present. Can J Psychiatry 1986;31:2-21.

2 Halliday JL: Psychosocial medicine. A study of the sick society. London, Heinemann, 1948.

3 Wittkower ED: Historical perspective of contemporary psychosomatic medicine. Int J Psychiatr Med 1974;5:309-319.

4 Engel GL: The concept of psychosomatic disorder. J Psychosom Res 1967;11:3-9.

5 Engel GL: The need for a new medical model: A challenge for biomedicine. Science 1977;196: 129-136.

6 Anderson NB, Armstead CA: Toward understanding the association of socioeconomic status and health. Psychosom Med 1995;57:213225.

7 Landrigan PJ: Environmental disease: A preventable epidemic. Am J Public Health 1992; 82:941-943.

8 Sternberg EM: Emotions and disease: From balance of humors to balance of molecules. Nat Med 1997;3:264-267.

9 Solomon GF: Whither psychoneuroimmunology? A new era of immunology, of psychosomatic medicine, and of neuroscience. Brain Behav Immun 1993; 7:352-366.

10 Ader R, Cohen N, Felten D: Psychoneuroimmunology: Interactions between the nervous system and the immune system. Lancet 1995; 354:99-103.

11 Sonino N, Fava GA: Psychological aspects of endocrine disease. Clin Endocrinol 1998;49:17.

12 Fava GA: Lipowski's legacy: The psychosomatic spirit. Psychother Psychosom 1999;68:1-2.

13 Lipowski ZJ: Psychosomatic medicine in the seventies: An overview. Am J Psychiatry 1977; 134:233-244.

14 Kissen DM: The significance of syndrome shift and late syndrome association in psychosomatic medicine. J Nerv Ment Dis 1963;136:3442.

15 Wise TN, Freyberger H (eds): ConsultationLiaison throughout the World. Basel, Karger, 1983.

16 Schwartz GE, Weiss SM: Yale conference on behavioral medicine: A proposed definition and statement of goals. J Behav Med 1978;1: 3-11.

17 Miller NE: Behavioral medicine: Symbiosis between laboratory and clinic. Annu Rev Psychol 1983;34:1-31.
18 Pert CB, Drehert HE, Ruff MR: The psychosomatic network: Foundations of mind-body medicine. Alternative Ther Health Med 1998; 4:30-41.

19 Dossey L: A journal and a journey. Alternative Ther Health Med 1995;1:6-9.

20 Galland L: The Four Pillars of Healing. New York, Random House, 1997.

21 Gordon JS: Manifesto for a New Medicine. Reading, Addison-Wesley, 1996.

22 Weil A: Spontaneous Healing. New York, Fawcett-Columbine, 1995

23 Eisenberg DM, Davis RB, Ettner SL, Appel S, Wilkey S, Van Rompay M, Kessler RC: Trends in alternative medicine use in the United States, 1990-1997. JAMA 1998;280:15691575 .

24 Astin JA, Marie A, Pelletier KR, Hansen U, Haskell WL: A review of the incorporation of complementary and alternative medicine by mainstream physicians. Arch Intern Med 1998; 158:2303-2310.

25 Bram I: Psychic trauma in pathogenesis of exophthalmic goiter. Endocrinology 1927;11: 106-116.

26 Paykel ES: Methodology of life events research; in Fava GA, Wise TN (eds): Research Paradigms in Psychosomatic Medicine. Basel, Karger, 1987, pp 13-29.

27 Winsa B, Adami HO, Bergstrom R, Gamsted A, Dahlberg PA, Adamson U, Jansson R, Kalsson A: Stressful life events and Graves' disease. Lancet 1991;338:1475-1479.

28 Sonino N, Girelli ME, Boscaro M, Fallo F, Busnardo B, Fava GA: Life events in the pathogenesis of Graves' disease. A controlled study. Acta Endocrinol 1993;128:293-296.

29 Kung AWC: Life events, daily stresses and coping in patients with Graves' disease. Clin Endocrinol 1995;42:303-308.

30 Radosavljevic VR, Jakovic SM, Marinkovic JM: Stressful life events in the pathogenesis of Graves' disease. Eur J Endocrinol 1996;134: 699-701.

31 Sonino N, Fava GA, Boscaro M: A role for life events in the pathogenesis of Cushing's disease. Clin Endocrinol 1993;38:261-264.

32 Chrousos GP, Gold PW: The concept of stress and stress system disorders. JAMA 1992;267: 1244-1252.

33 Reichlin S: Neuroendocrine-immune interactions. N Engl J Med 1993;329:1246-1253.
34 Schmidt-Ott G, Jacobs R, Jager B, Klages S, Wolf J, Werfel T, Kapp A, Schurmeyer T, Lamprecht F, Schmidt RE, Schedlowski M: Stressinduced endocrine and immunological changes in psoriasis patients and healthy controls. Psychother Psychosom 1998;67:37-42.

35 Biondi M, Zannino LG: Psychological stress, neuroimmunomodulation, and susceptibility to infectious diseases in animals and man. Psychother Psychosom 1997;66:3-26.

36 McEwen BS, Stellar E: Stress and the individual. Mechanisms leading to disease. Arch Intern Med 1993;153:2093-2101.

37 Hubbard JR, Workman EA (eds): Handbook of Stress Medicine. Boca Raton, CRC Press, 1998.

38 Sonino N, Fava GA, Boscaro M, Fallo F: Life events and neurocirculatory asthenia. A controlled study. J Intern Med 1998;244:523-528.

39 Rozanski A, Blumenthal JA, Kaplan J: Impact of psychological factors on the pathogenesis of cardiovascular disease and implications for therapy. Circulation 1999;99:2192-2217.

40 Wright RJ, Rodriguez M, Cohen S: Review of psychosocial stress and asthma. Thorax 1998; 53:1066-1074.

41 Wagner BM: Major and daily stress and psychopathology. Stress Med 1990;6:217-226.

42 De Jong GM, Van Sonderen E, Emmelkamp PMG: A comprehensive model of stress. Psychother Psychosom 1999;68:290-298.

43 Berckman LF: The role of social relations in health promotion. Psychosom Med 1995;57: 245-254.

44 Scheier MF, Bridges MW: Person variables and health. Psychosom Med 1995;57:255-268.

45 Cassel J: The contribution of the social environment to host resistance. Am J Epidemiol 1976;104:107-123.

46 McEwen BS: Protective and damaging effects of stress mediators. N Engl J Med 1998;338: 171-179.

47 Kelly S, Hertzman C, Daniels M: Searching for the biological pathways between stress and health. Annu Rev Public Health 1997;18:437462.

48 Johnston-Brooks CH, Lewis MA, Evans GW, Whalen CK: Chronic stress and illness in children: The role of allostatic load. Psychosom Med 1998;60:597-603. 
49 Biondi M, Picardi A: Psychosocial stress and neuroendocrine function in humans: The last two decades of research. Psychother Psychosom 1999;68:114-150.

50 Jonsson BH, Theorell T: Low plasma prolactin levels in patients with functional dyspepsia. Psychother Psychosom 1999;68:151-156.

51 Christodoulou GN, Dragonas TG: Role of early development factors in susceptibility to disease; in Fava GA, Freyberger H (eds): Handbook of Psychosomatic Medicine. Madison, International Universities Press, 1998, pp 191203.

52 Hofer M: Animal models in the understanding of human disease. Psychiatr Clin North Am 1979;2:211-226.

53 Williams RB: The role of psychosocial factors in human disease: Lessons from animal models. Acta Physiol Scand 1997;(suppl 640):100102.

54 Plotsky PM, Meaney MJ: Early, postnatal experience alters hypothalamic corticotropin-releasing factors (CRF) in RNA, median eminence CRF content and stress-induced release in adult rats. Mol Brain Res 1993;18:195-200.

55 Heim C, Owens MJ, Plotsky PM, Nemeroff $\mathrm{CB}$ : Persistent changes in corticotropin-releasing factor systems due to early life stress. Psychopharmacol Bull 1997;33:185-192.

56 Sonino N, Fava GA: Psychosomatic aspects of Cushing's disease. Psychother Psychosom 1998;67:140-146.

57 Sobrinho L: Emotional aspects of hyperprolactinemia. Psychother Psychosom 1998;67:133139.

58 McCauley J, Kern DE, Kolodner K, Dill L, Schroeder AF, De Chant HK, Ryden J, Derogatis LR, Bass EB: Clinical characteristics of women with a history of childhood abuse. JAMA 1997;277:1362-1368.

59 Engel GL: Psychogenic pain and the pain prone patient. Am J Med 1959;26: 899-918.

60 Salmon P, Calderbank S: The relationship of childhood physical and sexual abuse to adult illness behavior. J Psychosom Res 1996;40: 329-336.

61 Fava GA, Freyberger HJ, Bech P, Christodoulou G, Sensky T, Theorell T, Wise TN: Diagnostic criteria for use in psychosomatic research. Psychother Psychosom 1995;63:1-8.

62 Littman AB: Review of psychosomatic aspects of cardiovascular disease. Psychother Psychosom 1993;60:148-167.

63 Johnston DW: The current status of the coronary prone behaviour pattern. J R Soc Med 1993;86:406-409.

64 Hemingway H, Marmot M: Psychosocial factors in the etiology and prognosis of coronary heart disease. BMJ 1999;318:1460-1467.

65 Taylor GJ, Bagby RM, Parker JDA: Disorders of Affect Regulation. Cambridge, Cambridge University Press, 1997.

66 Sifneos PE: The prevalence of alexithymic characteristics in psychosomatic patients. Psychother Psychosom 1973;22:255-262.

67 Greer J: Cancer and the mind. Br J Psychiatry 1983;143:535-543.
68 Berry DS, Pennabaker JW: Non verbal and emotional expression and health; in Fava GA, Freyberger H (eds): Handbook of Psychosomatic Medicine. Madison, International Universities Press, 1998, pp 69-84.

69 Greer S, Morris T: Psychological attributes of women who develop breast cancer. A controlled study. J Psychosom Res 1975;19:147153.

70 Weiner H: Specificity and specification: Two continuing problems in psychosomatic research. Psychosom Med 1992;54:567-587.

71 Pettingale KW: Coping and cancer prognosis. J Psychosom Res 1984;28:363-364.

72 Bernard B, Vorst HCM, Vingerhoets AJJM, Gerritsen W: The Amsterdam alexithymia scale. Psychother Psychosom 1999;68:241251

73 Naatanen P, Ryynanen A, Keltikangas-Jarvinen L: The influence of alexithymic characteristics on the self-perception and facial expression of a physiological stress state. Psychother Psychosom 1999;68:252-262.

74 Honkalampi K, Saarinen P, Hintikka J, Virtanene V, Viinamaki H: Factors associated with alexithymia in patients suffering from depression. Psychother Psychosom 1999;68:270275.

75 Iancu I, Horesh N, Offer D, Dannon PN, Lepkifker E, Kotler M: Alexithymia, affect intensity and emotional range in suicidal patients. Psychother Psychosom 1999;68:276-280.

76 Berenbaum H, Davis R, McGrew J: Alexithymia and the interpretation of hostile-provoking situations. Psychother Psychosom 1999;67: 254-258.

77 Verissimo R, Mota Cardoso R, Taylor G: Relationships between alexithymia, emotional control, and quality in life in patients with inflammatory bowel disease. Psychother Psychosom 1998;67:75-80

78 Kooiman CG, Spinhoven P, Trujsburg RW, Roojmans HGM: Perceived parental attitude, alexithymia and defense style in psychiatric outpatients. Psychother Psychosom 1998;67: 81-87.

79 World Health Organization: World Health Organization Constitution. Geneva, World Health Organization, 1948, p 28.

80 Ryff CD, Singer B: Psychological well-being. Psychother Psychosom 1996;65:14-23.

81 Fava GA: The concept of recovery in affective disorders. Psychother Psychosom 1996;65:213.

82 Fava GA: The concept of psychosomatic disorder. Psychother Psychosom 1992;58:1-12.

83 Ryff CD, Singer B: The contours of positive human health. Psychol Inquiry 1998;9:1-28.

84 Spiegel D, Kraemen HC, Bloom T, Gottheil E: Effect of a psychosocial treatment on survival of patients with metastatic breast cancer. Lancet 1989;ii:888-891.

85 Ramirez AJ, Craig TKJ, Watson JP, Fentiman IS, North WR, Rubens RD: Stress and relapse of breast cancer. BMJ 1989;298:291-294.

86 Stilley CS, Miller DJ, Manzetti JD, Marino IR, Keenan RJ: Optimism and coping styles. Psychother Psychosom 1999;68:299-303.
87 Heszen-Niejodek I, Gottschalk LA, Januszek M: Anxiety and hope during the course of three different medical illnesses. Psychother Psychosom 1999;68:304-312.

88 Majani G, Pierobon A, Giardini A, Callegari S, Opasich C, Cobelli F, Tavazzi L: Relationship between psychological profile and cardiological variables in chronic heart failure. Eur Heart J 1999;20:1579-1586.

89 Majani G, Pierobon A, Giardini A, Callegari S: Satisfaction profile (SAT-P) in 732 patients: Focus on subjectivity in HRQOL assessment. Psychol Health, in press.

90 Steptoe A, Wardle J: Cognitive predictors of health behavior in contrasting regions of Europe. Br J Clin Psychol 1992;31:485-502.

91 Jenkins CD: New horizons in psychosomatic medicine. Psychosom Med 1985;47:3-25.

92 Lipowski ZJ: Physical illness, the patient and his environment; in Reiser MF (ed): American Handbook of Psychiatry, vol 4. New York, Basic Books, 1975, pp 3-42.

93 Lishman WA: Organic Psychiatry. The Psychological Consequences of Cerebral Disorders. Oxford, Blackwell, 1998.

94 Lipowski ZJ: A new look at organic brain syndromes. Am J Psychiatry 1980;137:674-678.

95 Fava GA, Sonino N: Depression associated with medical illness. CNS Drugs 1996;5:175189.

96 Robertson MM, Katona CLE (eds): Depression and Physical Illness. Chichester, Wiley, 1997.

97 Lipowski ZJ: Physical illness and psychopathology. Int J Psychiatr Med 1974;5:483497.

98 Musselman DL, Evans DL, Nemeroff CB: The relationship of depression to cardiovascular disease. Arch Gen Psychiatry 1998;55: 580-592.

99 Ford DE, Mead LA, Chang PP, CooperPatrick L, Wang NY, Klag MJ: Depression is a risk factor for coronary artery disease in men. Arch Intern Med 1998;158:1422-1426.

100 Lesperance F, Frasure-Smith N, Talajic M: Major depression before and after myocardial infarction. Psychosom Med 1996;58:99-110.

101 Sonino N, Fava GA, Raffi AR, Boscaro M, Fallo F: Clinical correlates of major depression in Cushing's disease. Psychopathology 1998;31:302-306.

102 Sonino N, Zielezny M, Fava GA, Fallo F, Boscaro M: Risk factors and long-term outcome in pituitary-dependent Cushing's disease. J Clin Endocrinol Metab 1996;81:26472652.

103 Kellner R: Psychosomatic syndromes, somatization and somatoform disorders. Psychother Psychosom 1994;61:4-24.

104 American Psychiatric Association: Diagnostic and Statistical Manual of Mental Disorders (DSM-IV). Washington, American Psychiatric Association, 1994.

105 Judd LL: Subsyndromal symptomatic depression. CNS Drugs 1994;1:399-404.

106 Fava GA: Subclinical symptoms in mood disorders: Pathophysiological and therapeutic implications. Psychol Med 1999;29:47-61. 
107 Fava GA: Irritable mood and physical illness. Stress Med 1987;3:293-299.

108 Fava GA, Mangelli L: Subclinical symptoms of panic disorder. Psychother Psychosom 1999;68:281-289.

109 Manuck SB, Marsland Al, Kaplan JR, Williams JK: The pathogenicity of behavior and its neuroendocrine mediation: An example from coronary heart disease. Psychosom Med 1995;57:275-283.

110 Jalkanen J, Salonen R, Kaplan GA, Chesney MA, Salonen JT: Hostility and the progression of carotid atherosclerosis. Psychosom Med 1994;56:519-525.

111 Fava M, Rosenbaum JF, McCarthy M, Pava $\mathrm{J}$, Steingard R, Bless E: Anger attacks in depressed outpatients and their response to fluoxetine. Psychopharmacol Bull 1991;27: 275-279.

112 Williams RB: Neurobiology, cellular and molecular biology, and psychosomatic medicine. Psychosom Med 1994;56:308-315.

113 Schmale AH: Giving up as a final common pathway in changes in health; in Lipowski ZJ (ed): Psychosocial Aspects of Physical Illness. Basel, Karger, 1972, pp 20-40.

114 Bech P: Measurement of psychological distress and well-being. Psychother Psychosom 1990;54:77-89.

115 Appels A: Mental precursors of myocardial infarction. Br J Psychiatry 1990;156:465471.

116 Porcelli P, De Carne M, Fava GA: Assessing somatization in functional gastrointestinal disorders: Integration of different criteria. Psychother Psychosom 2000;69:198-204.

117 Bjorntorp P: The android woman. A risky condition. J Intern Med 1996;239:105-110.

118 Mechanic D, Volkart EH: Illness behavior and medical diagnosis. J Health Hum Behav 1980;1:86-94.

119 Kellner R: Somatization and Hypochondriasis. New York, Praeger, 1986.

120 Pilowsky I: Abnormal illness behavior. Chichester, Wiley, 1997.

121 Goldbeck R: Denial in physical illness. J Psychosom Res 1997;43:575-593.

122 Muskin PR, Feldhammer T, Golfand JL, Strauss DH: Maladaptive denial of physical illness: A useful new diagnosis. Int J Psychiatr Med 1998;20:463-477.

123 Blackwell B: Compliance; in Fava GA, Freyberger $\mathrm{H}$ (eds): Handbook of Psychosomatic Medicine. Madison, International Universities Press, 1998, pp 625-638.

124 Emdad R, Belkic K, Theorell T, Cizinsky S: What prevents professional drivers from following physicians' cardiologic advice? Psychother Psychosom 1998;67:226-240.

125 Büchi S, Sensky T, Sharpe L, Timberlake N: Graphic representation of illness: A novel method of measuring patients' perceptions of the impact of illness. Psychother Psychosom 1998;67:222-225.

126 Schnyder U, Büchi S, Mörgeli H, Sensky T, Klaghofer R: Sense of coherence. A mediator between disability and handicap? Psychother Psychosom 1999;68:102-110.
127 Muldoon MF, Barger SD, Flory JD, Manuck SB: What are quality of life measurements measuring? BMJ 1998;316:542-545.

128 Leplege A, Hunt S: The problem of quality of life in medicine. JAMA 1997;278:47-50.

129 Viemero V, Krause C: Quality of life in individuals with physical disabilities. Psychother Psychosom 1998;67:317-322.

130 Burman P, Deijen JB: Quality of life and cognitive function in patients with pituitary insufficiency. Psychother Psychosom 1998;67: 154-167.

131 Lipowski ZJ: Psychosocial aspects of disease. Ann Intern Med 1969;71:1197-1296.

132 Fava GA: Methodological and conceptual issues in research on quality of life. Psychother Psychosom 1990:54:70-76.

133 Gill TM, Feinstein AR: A critical appraisal of the quality of quality-of-life measurements. JAMA 1994;272:619-626.

134 Lipowski ZJ: Current trends in consultationliaison psychiatry. Can J Psychiatry 1983;28: 329-338.

135 Wise TN: Consultation-liaison research. Psychother Psychosom 1995;63:9-21.

136 Shore JH: Psychiatry at a crossroad: Our role in primary care. Am J Psychiatry 1996;11: 1398-1403.

137 Fava GA: Medical-psychiatric service. Psychother Psychosom 1987;48:96-100.

138 Theorell T: Critical life changes. Psychother Psychosom 1992;57:108-117.

139 Compas BE, Haagon DA, Keefe FJ, Leitenberg H, Williams DA: Sampling of empirically supported psychological treatments from health psychology: Smoking, chronic pain, cancer, and bulimia nervosa. J Consult Clin Psychol 1998;66:89-112.

140 Mayou R, Smith EOP: Hospital doctors' management of psychological problems. Br J Psychiatry 1986;148:194-197.

141 O'Malley PG, Jackson JL, Kroenke K, Yoon IK, Hornstein E, Dennis GJ: The value of screening for psychiatric disorders in rheumatology referrals. Arch Intern Med 1998;158: 2357-2362.

142 Emmelkamp PMG, Van Oppen P: Cognitive interventions in behavioral medicine. Psychother Psychosom 1993;59:116-130.

143 Cottraux J: Behavioral psychotherapy applications in the medically ill. Psychother Psychosom 1993;60:116-128.

144 Covino NA, Frankel FH: Hypnosis and relaxation in the medically ill. Psychother Psychosom 1993;60:75-90.

145 Blanchard EB: Behavioral medicine and health psychology; in Bergin AE, Garfield JL (eds): Handbook of Psychotherapy and Behavior Change. New York, Wiley, 1994, pp 701-733.

146 Richardson JL, Shelton DR, Krailo M, Levine AM: The effect of compliance with treatment on survival among patients with hematologic malignancies. J Clin Oncol 1990;8: 356-364.
147 Fawzy FF, Fawzy NS, Hyun CS, Elashoff M, Guthrie D, Fahey JL, Morton D: Malignant melanoma. Effects of an early structured psychiatric intervention, coping, and affective state on recurrence and survival 6 years later. Arch Gen Psychiatry 1993;50:681-689.

148 Lustman PJ, Griffith LS, Freedland KE, Kissel SS, Clouse RE: Cognitive behavior therapy for depression in type 2 diabetes mellitus. Ann Intern Med 1998;129:613-621.

149 Van Peski-Oosterbaan AS, Spinhoven P, van der Does AJW, Bruschve AVG, Roojmans HGM: Cognitive change following cognitive behavioral therapy for non-cardiac chest pain. Psychother Psychosom 1999;68:214220.

150 Smyth JM, Stone AA, Hurewitz A, Kaell A: Effects of writing about stressful experiences on symptom reduction in patients with asthma or rheumatoid arthritis. JAMA 1999;281: 1304-1309.

151 Frank JD, Frank B: Persuasion and healing. Baltimore, The Johns Hopkins University Press, 1991.

152 Fava GA: Cognitive-behavioral therapy; in Fink M (ed): Encyclopedia of Stress. San Diego, Academic Press, 2000, pp 484-487.

153 Egbert LD, Battit GE, Welch CE, Bartlett MK: Reduction of postoperative pain by encouragement and instruction of patients. N Engl J Med 1964;270:825-827.

154 Mirò J, Raich RM: Preoperative preparation for surgery: An analysis of the effects of relaxation and information provision. Clin Psychol Psychother 1999;6:202-209.

155 Marks I: Is a paradigm shift occurring in brief psychological treatments? Psychother Psychosom 1999;68:169-170.

156 Astin JA, Shapiro SL, Lee RA, Shapiro DH: The construct of control in mind-body medicine: Implications for health care. Alternative Ther Health Med 1999;5:42-47.

157 Fava GA, Rafanelli C, Cazzaro M, Conti S, Grandi S: Well-being therapy. Psychol Med 1998;28:475-480.

158 Fava GA: Well-being therapy. Conceptual and technical issues. Psychother Psychosom 1999;68:171-179.

159 Fava GA: Sequential treatment. Psychother Psychosom 1999;68:227-229.

160 Fava GA: The definition, diagnosis and clinical relevance of somatoform disorders. Rev Contemp Pharmacother 1996;7:269-277.

161 Kroenke K, Swindle R: Cognitive-behavioral therapy for somatization and symptom syndromes: A critical review of controlled clinical trials. Psychother Psychosom 2000;69: 205-215.

162 Warwick HM, Clark DM, Cobb AM, Salkovskis PM: A controlled trial of cognitive-behavioral treatment of hypochondriasis. Br J Psychiatry 1996;169:189-195.

163 Avia MD, Ruiz MA, Olivares ME, Crespo M, Guisado AB, Sanchez A, Varela A: The meaning of psychological symptoms. Behav Res Ther 1996;34:23-31.

164 Bouman TK, Visser S: Cognitive and behavioral treatment of hypochondriasis. Psychother Psychosom 1998;67:214-221. 
165 Clark DM, Salkovskis PM, Hackmann A, Wells A, Fennel M, Ludgate J, Ahmad S, Richards HC, Gelder M: Two psychological treatments for hypochondriasis. Br J Psychiatry 1998;173:218-225.

166 Fava GA, Grandi S, Rafanelli C, Fabbri S, Cazzaro M: Explanatory therapy of hypochondriasis. J Clin Psychiatry 2000;61:317322.

167 Fava GA, Grandi S: Differential diagnosis of hypochondriacal fears and beliefs. Psychother Psychosom 1991;55:114-119.

168 Shader RI, Weinberger DR, Greenblatt DJ: Psychopharmacological approaches to the medically ill patient; in Karasu TB, Steinmuller RI (eds): Psychotherapeutics in Medicine. New York, Grune and Stratton, 1978, pp 117-155.

169 Silver PA (ed): Psychotropic Drug Use in the Medically Ill. Basel, Karger, 1994.

170 Ananth J: Psychopharmacological agents in physical disorders; in Fava GA, Freyberger $\mathrm{H}$ (eds): Handbook of Psychosomatic Medicine. Madison, International Universities Press, 1998, pp 593-624.

171 Lechin F, van der Dijs B, Lechin ME: Plasma neurotransmitters and functional illness. Psychother Psychosom 1997;65:293-318.
172 Holsboer F: The rationale for corticotropinreleasing-hormone receptor (CRH-R) antagonists to treat depression and anxiety. J Psychiat Res 1999;33:181-214.

173 Feinstein AR: Twentieth century paradigms that threaten both scientific and humane medicine in the twenty-first century. J Clin Epidemiol 1996;49:615-617.

174 Kellner R: Somatization: The most costly comorbidity? in Maser JD, Cloninger CR (eds): Comorbidity of Mood and Anxiety Disorders. American Psychiatric Press, 1990, pp 239-252.

175 Katon WJ, Walker EA: Medically unexplained symptoms in primary care. J Clin Psychiatry 1998;59(suppl 20):15-21.

176 Kroenke K, Mangelsdorff D: Common symptoms in ambulatory care. Am J Med 1989;86: 262-268.

177 Randall JL: Evolution of the new paradigm. Primary Care 1996;23:183-198.

178 Given BA, Given CW: Health promotion for family caregivers of chronically ill elders. Annu Rev Nurs Res 1998;16:197-217.

179 Weitzner MA, Knutzen R: The impact of pituitary disease on the family caregivers and the overall family functioning. Psychother Psychosom 1998;67:181-188.
180 Lopez Castillo J, Gurpegni M, Ayuso-Mateos JL, Lunn JD, Catalan J: Emotional distress and occupational burnout in health care professionals serving HIV-infected patients. Psychother Psychosom 1999;68:248-256.

181 Thomsen S, Soares J, Nolan P, Dallender J, Arnetz B: Feelings of professional fulfillment and exhaustion in mental health personnel. Psychother Psychosom 1999;68:157-164.

182 Breslow L: From disease prevention to health promotion. JAMA 1999;281:1030-1033.

183 Reiser MF: Psychosomatic medicine: A meeting ground for oriental and occidental medical theory and practice. Psychother Psychosom 1979;31:315-323.

184 Fava GA, Wise TN (eds): Research paradigms in psychosomatic medicine. Advances in Psychosomatic Medicine. Basel, Karger, 1987, vol. 17

185 Fava GA: Swimming against the tide. Psychother Psychosom 1999;68:57-58.

186 Engel GL: How much longer must medicine's science be bound by a seventeenth century world view? Psychother Psychosom 1992;57: 3-16. 